\author{
HARJinder KaUR-AuJla*, FARZANa Shain \& A. Kate LiLlie
}

\author{
A GAP EXPOSED

\section{What Is Known About Sikh Victims of Domestic Violence Abuse (DVA) and Their Mental Health?}

\author{
(Received: 3 November 2018; accepted: 18 March 2019)
}

There is emerging evidence that Domestic Violence and Abuse (DVA) has the potential to pose a real threat to the Sikh community as it seeks to ensure that gender equality is embraced within its religious practice. Nevertheless, the interface of domestic abuse and the distress it causes to Sikh female victims in relation to their mental health is barely explored within UK academic literature. From the existing literature on DVA and South Asian women, what we do know is that there may be a denial of the issue within communities due to shame and family exposure. We are aware of the high rates of suicide and self-harm that is prevalent within the South Asian culture, something often attributed to inter-familiar conflict.

The pioneering community-led British Sikh Report or BSR (British Sikh Report 2017) surveyed 2000 Sikhs and found that seventy-two percent of Sikh-identifying males and females considered that violence and sexism affected British Sikh women's lives. Notably, the type of violence was not particularised enough to be able to gain a full understanding and extent of the issue. A further eighty-three percent of male and female participants felt that women should be provided mental health support in Gurdwaras (temples). This grassroot report has been presented to Parliament and was pioneered by local MP's and is clearly topical in terms of study.

To date, we are aware of no UK-based academic study that focuses on the experiences of Sikh victims of abuse. This paper aims to extrapolate key generic studies on domestic abuse in the South Asian culture, in order to help formulate an initial understanding of issues involving domestic violence and mental health as it impacts Sikh women in Britain. Further recommendations for research within this community are presented.

Keywords: domestic abuse, violence, VAW, religion, South Asian, Sikh, women, mental health, psychiatry, culture

* Corresponding author: Harjinder Kaur-Aujla, Keele University, Staffordshire, ST5 5BG,

United Kingdom; harjaujla@yahoo.co.uk. 


\section{Rationale}

This conundrum of 'we don't have mental health or domestic abuse issues in our Sikh community', is slowly being shifted through self-report surveys such as the BSR. This article explores the plethora of research that exists around 'South Asian women' and domestic abuse; it examines the difficulties with this homogenous label whilst extracting limited literature to inform us of the experiences of domestic abuse and mental health. The label 'South Asian women' presents many problems in terms of capturing the Sikh woman's journey in relation to domestic abuse. Whilst some of the issues are similar, the religious content is built around equality. So how is it that a religion that advocates equality continues to have power relations between men and women? We begin to extricate the literature around South Asian women and identify gaps in research that need to be addressed if we are to understand the issues faced by Sikh victims of abuse.

\section{The Sikh Population}

According to Census data published in 2011, 420,000 Sikhs resided in the UK, and over half were British-born. Other anecdotal reports have stipulated a larger population; however, the sources' evidence base is not clear. Yet the literature has revealed a low uptake of services for South Asian women; therefore, they do not reach out until a point of crisis, often on the cusp of suicide and/ or self-harm (CHEW-GRAHAM et al 2002). The application of these findings to the Sikh community is constricted as it is difficult to siphon from the research which views represent this group specifically.

Sikhism is a fairly new religion that was founded by Guru (teacher) Nanak Dev $\mathrm{Ji}$ in the $15^{\text {th }}$ Century. Notably, it is not a homogenous group as differences exist within the group to consider, whether baptised or non-baptised Sikhs. Sikhs can adopt the Sikh way of life; however, some are baptised, many of which are practicing Sikhs and wear all the $5 \mathrm{~K}$ 's - Kesh (long uncut hair), Kara (silver bracelet that represents equality), Kanga (a small comb in hair), Kirpan (small sword) and Kaccha (cotton underwear).

Moreover, the key principle of this religion is to give men and women equal status. The name Singh (Lion) was given to males to replace the family surname, and Kaur (Princess) to females. The idea at the time was to eliminate caste differences that were allocated to certain surnames with a view to create equality in society. Equally, this meant that a woman did not have to change her surname post marriage, which again was aimed to give her equal standing in society. There is an expectation that a male will carry on the 'man's' name; therefore, when a daughter is born, this is felt to be a challenge to his existence and sense of entitlement. This highlights the discrepancy between culture and religion, because the Sikh Gurus objected against this practice: 'You are my beloved, my daughters. You must be respected. How can this world be without you? You do not have to take anybody else's name. You are an 
individual, you are the equivalent of a prince, and you keep Kaur (princess) as your given name' ('Guru Gobind Singh Ji' in Encyclopaedia Britannica 2015).

However, arguably, cultural practice has contradicted this in the 'religious instruction' that there is an expectation of her to marry and the father to pay for her wedding, a subtle form of 'dowry' particularly in India, (BANERJEE 2013; RAWAL \& SINGH 2013). Throughout her life, ceremonies are performed that reinforce males as being superior. The act of 'rakri', tying a thread on a brother so he can protect her and she gets a gift in return, is a dependency on a male to be stronger. The celebration of 'lohri' is interesting as it celebrates the birth of a boy in the family, yet there is no single celebration that marks the birth of a girl. The female child is reminded that she will be leaving the maternal home to marry and is prepared for this by learning to cook, observing her mother being subservient to her father, doing the chores, and maintaining the honour of the family. Her individuality as a female is thwarted by the need to conform and remain in the parameters of culture - a patriarchal culture. The process of marriage and her role in the marital home is constrained to living up to the expectations of her husband and newly formed extended family. Clearly an abundance of evidence exist that South Asian Women experience domestic abuse both from their partner and family members - it is rarely in isolation, (MIRZA 2016; IzZIDIEN 2008). It is likely then that abuse in South Asian families precipitates mental health issues, and then the stigma of the lack of mental health, and perhaps 'community disgust' used as a tool to further control the victim. The THIARA and GILL (2012) report on child contact revealed the post-separation DVA issues and delivers interesting accounts of South Asian women's experiences.

\section{Defining Domestic Abuse (DVA)?}

According to the World Health Organisation (2016), domestic violence globally affects one in three women. The cross-government definition of 'domestic violence and abuse' (DVA) is any incident or pattern of controlling, coercive, or threatening behaviour, including violence or abuse of those aged 16 or over, who are or have been intimate members of the same family regardless of gender or sexuality (Information for Local Areas on the Change to the Definition of Domestic Violence and Abuse 2013). This definition is similar to what is being used in academic literature and domestic abuse agencies; we adopt it in this paper.

Alternative definitions such as Domestic Violence (DV), Violence Against Women (VAW), may not fully encapsulate emotional and coercive abuse. It is evident in the literature on domestic abuse that emotional and psychological abuse may be just as, if not more, distressing to victims of abuse than physical abuse (GoODMAN et al. 1999). The Office of National Statistics (ONS) nationally adopts the definition of 'domestic abuse' (DA), with a view to incorporate coercive control in future data collation.

The intricacies of domestic abuse need further exploration within the context of South Asian culture, which incorporates inter-familiar conflict, isolation, and specific 
cultural issues surrounding shame, honour, or 'izzat'. GILBERT and colleagues (2004) defined 'izzat' in relation to how their participants phrased it to be as a learned set of rules that community members embrace in order to protect family honour and social positioning. GILBERT and colleagues (2004) found that a loss of honour (izzat), and therefore avoidance of shame (sharam), were the key fear factors when accessing mental health services. Similarly, it is argued that the disclosure of domestic violence and breaking the set rules that maintain izzat can equally keep a woman in a domestic abuse situation and constrain her independence (GILL 2004). The research on 'honour-based violence' often looks at the most serious form of violence where breaches to these set codes have occurred, and often women have been killed to maintain family honour. Expanding on this, the term 'honour-based abuse' is preferred since this helps to embrace and identify every-day breaches of the perpetrators' set rules (and beliefs) that lead to abusing the victim. The cultural codes that are broken within the Sikh community would be really useful to explore from the victim's perspective.

Hence, throughout this paper, the term 'domestic abuse' (Information for Local Areas on the Change to the Definition of Domestic Violence and Abuse 2013), is used to ensure all aspects of abuse are captured in the definition, and not exclusively violence. This definition of abuse also incorporates culturally specific forms of abuse such as shame-based or honour-based explanations, as previously defined.

\section{What is the Relationship between DVA and Mental Health?}

Several disputes occur around the area of domestic abuse and its relationship with mental health. According to HEGARTY (2011), domestic violence is commonly associated with severe mental illness; however, this is often under-researched and not routinely screened for in clinical practice. Mainly, the researchers' focus has been on the debate whether mental health issues occur as a result of abuse or whether women who already have mental health issues are more susceptible to abuse. TREVILLION and colleagues (2012) published a systematic review in the area of domestic violence and mental health in a study funded over five years. They found that domestic violence can not only lead to the development of mental health problems, but that people with mental health problems are also more likely to be abused. DILLON and colleagues (2013) conducted a literature search and reviewed seventy-five studies in the area of domestic abuse and poor mental/physical health of women from 2006-2012. Whilst variations were noted across cultures, it remains clear that domestic abuse was associated with depression, anxiety, PTSD, self-harm, and sleep disorders. Notably, it is not explicit whether these symptoms occurred as a result of the abuse or pre-trauma.

DEVRIES and colleagues (2013) refer to this bi-directional relationship between mental health and domestic violence, stating it is difficult to ascertain whether the domestic abuse causes mental health issues or whether predisposed factors make women more vulnerable to it. The pathologisation of women's mental health has been a regular tool in the armoury of abusive men (BANCROFT 2003). FERRARI and colleagues (2014) recommend, due to the high psychological morbidity, trauma 
informed interventions for survivors who seek support from DVA services. There may also be a need to provide trauma-informed interventions for women whilst they remain in the relationship; however, the efficacy of this needs further research. Notably, psychotherapeutic approaches - such as spiritual mediation, prayer and use of the religious scriptures - have been effectively used by therapists within this community (KALRA et al. 2012).

BANCROFT (2003) writes extensively on the key tools that abusive men use to control their victims. He gives a profile of the abusive male that oscillates between being 'Mr Right' to 'Abuser'. His work has laid the foundation for many perpetrator programmes and victim support programmes across the UK and USA. He has argued that men who abuse will rarely take responsibility for the abuse that they cause. It is a common tactic for them to minimise, deny, or lie about their abuse. They often lack empathy, although they are capable of mimicking emotion where there is a threat or goal. Bancroft highlights how their belief system often enables them to justify the abuse and asserted that untrained court officials and police are often fooled by their presentation. The most relevant point that Bancroft observes is that making a woman out to be unstable or getting her to question her mental health is a common strategy that abusive men use. This serves many functions: it gets the victim to question her own mental health, thus making her an easy target, and furthermore ensures that were she ever to disclose the abuse. her credibility would be questioned.

\section{What do we know about DVA within the South Asian population of the UK?}

The presence of cultural conflict or 'acculturation' is often identified as a prominent determiner to women's mental health. ANAND and COCHRANE (2005) reviewed a series of studies on mental health issues related to South Asian women in the UK, namely: depression, suicide, parasuicide, deliberate self-harm, and eating disorders. The recommendation of this review was to understand religious concepts that contribute to the understanding of South Asian Women's mental health, notwithstanding other factors such as developing culturally sensitive mental health services for South Asian women.

According to ANITHA and colleagues (2009), fifty percent of South Asian women in their study on seventy-two South Asian women reported physical abuse by their husbands, in-laws, or parental family in the case of forced marriage. Other types of abuse consisted of controlling behaviour, isolation, financial abuse, and verbal abuse. Notably, forty-three percent of women still stayed in the relationships within the context of this study, and the authors acknowledge the longitudinal need to study the mental health of women as an aftermath of domestic violence, too. This study also highlighted that women who continue to suffer domestic violence reported mental health problems including sleep issues, eating disorders, depression, extreme anger, panic, stress, memory loss, and suicidal thoughts or attempts. Notably, these are symptoms of posttraumatic stress disorder (PTSD); it is questionable as to whether treatment models take the impact of abuse on mental health into consideration 
(HuMPHREYS \& THIARA 2003). This research acknowledges the link between domestic violence, self-harm and trauma. In doing so it recognises the pitfalls of the medical model in the low level of trauma services, 'victim blaming' in terms of pathologising the victim, and making the role of abuse / perpetrator invisible. The over-reliance on medication rather than counselling is also identified as a concern. This study also emphasises that the presence of mental health issues in child contact disputes can add to the woman's fear of the children being taken away, or at times put in the perpetrator's care. There is very little information offered in this study about how these women coped with the abuse, or what their interpretation of the abuse was in a religious context.

Moreover, the need for culturally sensitive services that deal with mental health and domestic violence is advocated, yet the relationship between mental health and domestic violence, including women's interpretations of their mental health is lacking. It is pertinent to understand that one of the major barriers for South Asian women in terms of access to mainstream services is the expectation to leave the relationship when they need help to manage within it (IzZIDIEN 2008).

Whilst $2.3 \%$ of this sample were of Sikh origin, representative of the local community of Manchester, this study does not identify the unique struggle that a Sikh woman may have in a religion that advocates equality, as opposed to other religious groups - the differences between these religious groups don't seem to shine through. It is our concern, then, that the converging issues of domestic violence and mental health are fully understood so that appropriate methods of treatment can fully implemented for the daily struggle of South Asian women, including the often multiple perpetrators that may affect her mental health. BURMAN and colleagues (2004) found that domestic violence in South Asian culture is often excused under the notion of 'cultural privacy' and this needs to be a key priority in terms of access to women. Furthermore, to understand South Asian women as a homogeneous group means that the religious aspect of Sikhism and how this can be understood to work with victims and perpetrators needs further exploration.

\section{What do we know about mental health within the South Asian population of the UK?}

Most recently, RUPRAI (2016) looked at the Punjabi Sikh community and found that this community did not regard mainstream mental health services as relevant, and their religion helped them practice psychological well-being. Their historical influences led them to follow a life as 'warriors', thereby capable of managing hardships without the influence of services. Whilst this is a very small study, the pressure to manage the mental health issues within the community, and perhaps in the family, may mean that these then erect additional barriers for the Sikh community when accessing help. HuSSAIN and COCHRANE (2002), carried out a small-scale study to report that women of South Asian origin who experience mental health often used religion and prayer as a strategy to cope. 
Alarmingly, PANDE (2017) revealed that 80/240 (a third) of suicides in 2005 occurred on the Paddington rail line that runs through Southall and Slough, populated by a predominately Sikh community. This raised important questions, and it was found that a strong link exists between domestic violence and mental health. There is limited analysis on these suicides but PANDE identified abuse, dowry, abuse from the in-laws due to patriarchal norms, the victims' higher educational backgrounds, and a general lack of understanding of the victim's predicament.

Specifically, case examples of Sikh Women affected by domestic violence in the UK alone include Navjeet Sidhu (27), who threw herself on the railway track in Southall, taking her two children (5 and 18 months). The issues identified: her first child was not a boy, and therefore she suffered depression. It is important to note that the family and cultural pressure is what is likely to have made her depressed rather than not having a son. The inquest heard that the high expectations of her family and her husband's refusal to do housework were triggers to her actions. Navjeet Sidhu's mother, unable to cope with her grief, took her own life in the same place six months later. The media reported her husband as grief stricken and limited information about his role existed other than his sense of entitlement. There is an over-focus on 'her' mental health in media representations, including a diagnosis of OCD (Obsessive Compulsive Disorder) and depression. However, many women are diagnosed with mental illness and they do not necessarily commit suicide, thus suggesting we just do not go far enough to identify the real issues.

Furthermore, in the case of Karanjit Ahulawalia (UK), she committed homicide against her husband whom she saw as the perpetrator. After ten years of marriage, having had two sons and being subjected to severe physical and emotional abuse, Karanjit set him on fire in 1984 and was imprisoned for life. Following a later appeal, her sentence was reduced to manslaughter after a determination of increasing provocation and abuse by her ex-husband. Various cases, both in the UK and globally, demonstrate the perpetrators' narcissistic character traits and the toll they eventually take on the victim in terms of the most serious cases of crime / suicide (Gilchrist et al. 2003). Patterns of abuse are not that different to those of Western culture, the risk factors of abuse are often generated at a couple's point of separation, one's feeling of a loss of control, or jealousy: these can trigger a homicide. There needs to be an everyday analysis of abuse that can be proactive in Sikh communities rather than be reactive in their society. It is possible that unique triggers can be identified in this community so that the most serious cases of homicide or suicide might be avoided. From the literature so far, it has emerged that domestic abuse suicide attempts often were a response to violence rather than primarily mental illnesses.

Thereby, it is really important to acknowledge the research of MCKENZIE and colleagues (2003), who claim that suicide is less preventable in South Asian women. They iterated that warning signs are less obvious, thus making suicide prevention even more difficult in this group. It is therefore important that the timeline and journey of South Asian women experiencing mental health problems is duly understood. 


\section{What is the relationship between DVA and Mental Health in the South Asian Community?}

Despite some real weaknesses, the Casey report (CASEY 2016) vocalised a number of these hidden issues and asserted that more needs to be done about domestic abuse 'within' communities.

Bridging the gap between domestic abuse and mental health, MerRILL and OwENS (1986) identified that South Asian women were less likely to have a mental illness but their presentation is more symptomatic of the cultural conflict. BHUGRA and colleagues (1999) reported that married South Asian women were particularly at risk of suicide, again emphasising the role of the family unit. Thereafter, BHUGRA (2002) further found that cultural conflicts led to a sense of helplessness and hopelessness which further hindered help seeking. BHUGRA and DESAI (2002) identify the role of gender stereotyping, isolation from others, cultural conflict, poor self-esteem and domestic violence as factors in suicide. The inter-woven nature of cultural conflict and its impact on mental health is definitive and identifies a link between domestic abuse and mental health, yet the issues are dealt with separately.

When considering suicide then, there is a high prevalence of mental health difficulties, suicide and self-harm within the group of South Asian women. According to BHUGRA and colleagues (1999), attempted suicide rates among younger Asian women are 2.5 times higher than among white women, and seven times higher compared to South Asian men. In fact, socio-cultural factors were seen as more dominant in this group, rather than psychological factors. Furthermore, HuSAIN and colleagues (2006), reviewed rates of self-harm in British South Asian women and identified that they are more likely to self-harm than 'white' women. They apportioned contributory factors to poor mental health, marital problems, interference from mother-in-laws, and the pressure of arranged marriages. Self-harm was often used as a tool to alleviate the distress resulting from social isolation and the burden of responsibility to conform to societal expectations placed on South Asian women.

Furthermore, Hicks and BHUGRA (2003) interviewed highly educated South Asian women who attempted suicide. They identified depression, being trapped in an unhappy marriage situation, experience of violence from their husbands, and wider conflict with in-laws as factors. Again, mental health and violence are closely associated in this study. Both domestic violence and mental illness are hidden and complicated by 'parental, family, and community oppression' (BHARDWAJ 2001, 58). This illustrates that it is no surprise then that suicide occurrence is high in this group because there really is 'nowhere to run' until it's too late to seek an intervention. Thereby, South Asian women are likely to come into contact with services at a point of despair where self-taught coping strategies have failed.

In summary, whilst the family in Western culture can be considered as a method of support, it is evident from the literature that the South Asian family can, in effect, be a major barrier for South Asians seeking support. The specific needs of the South Asian community may not be met by mainstream services and a key barrier appears 
to be that the South Asian communities are often referred to as a homogenous group, whereas clear differences manifest in terms of beliefs and values that can be worked on. This may vary in different religious groups and there is a real need to particularise this homogenous group further so that they are best supported, and ready access to services is made more appealing.

So far, the literature in this area has revealed a grim picture of shame attached to mental health, and the intricacy of domestic violence being inter-familiar, and equally shameful. With the nature of power and control issues attached to domestic violence then, it is important to understand the timeline of the victim's mental health.

\section{Recommendations}

- Conduct idiosyncratic research on the experiences of domestic abuse within the Sikh religious group.

- Ascertain the extent to which this affects their mental health and how they cope, in light of the evidence suggesting that interventions are sought late in the South Asian community as a whole.

- Inform services about how to approach the Sikh population in light of the BSR highlighting that domestic abuse is an issue.

- Gain a better understanding of inter-familiar conflict that feeds into the victim's distress and the perpetrator's sense of power.

- Educate the Sikh Community about these threats and develop a community response to domestic abuse and mental health issues. Help them understand that 'mental distress' is a consequence of abuse and reduce the stigmatisation and isolation of the victim.

\section{References}

Anand, A.S. \& R. Cochrane (2005) 'The Mental Health Status of South Asian Women in Britain: A Review of the UK Literature', Psychology and Developing Societies 17, 195-214 (https:// doi.org/10.1177/097133360501700207).

Anitha, S., P. Chopra, W. Farouk, Q. Haq, S. Khan, A. Mahmood \& A. Mansoor (2009) Domestic Violence and Mental Health: Experiences of South Asian Women in Manchester: Report of the Community-Led Research Project on the Mental Health Needs of South Asian Women who are Survivors of Domestic Violence, retrieved 15 April 2019 from https:// lemosandcrane.co.uk/resources/Saheli\%20-\%20Domestic\%20violence\%20and\%20mental $\% 20$ health.pdf.

BAnCroft, L. (2003) Why does he Do that? Inside the Minds of Angry and Controlling Men (New York: Berkley).

BanerJee, P (2013) 'Dowry in 21st Century India: The Sociocultural Face of Exploitation', Trauma Violence Abuse 15, 34-40 (https://doi.org/10.1177/1524838013496334).

BHARDwAJ, A. (2001) 'Growing Up Young, Asian and Female in Britain: A Report on Self-Harm and Suicide'. Feminist Review 68, 52-67 (https://doi.org/10.1080/01417780110042392).

Bhugra, D., D.S. BALdwin, M. Desai \& K.S. JacoB (1999) 'Attempted Suicide in West London, II. Inter-Group Comparisons’, Psychological Medicine 29, 1131-39. 
BHugra, D. (2002) 'Suicidal Behavior in South Asians in the UK', Crisis: The Journal of Crisis Intervention and Suicide Prevention 23, 108-13 (http://dx.doi.org/10.1027//0227-5910.23.3.108).

Bhugra, D. \& M. Desai (2002) 'Attempted Suicide in South Asian Women', Advances in Psychiatric Treatment 8, 418-23 (https://doi.org/10.1192/apt.8.6.418).

British Sikh Report: An Insight into the British Sikh Community (2017) retrieved 26 April 2018 from http://www.britishsikhreport.org/wp-content/uploads/2017/03/British-Sikh-Report2017-Online.pdf.

Burman, E., S.L. Smailes \& K. Chantler (2004) “ “Culture” as a Barrier to Service Provision and Delivery: Domestic Violence Services for Minoritized Women', Critical Social Policy 24, 332-57 (https://doi.org/10.1177/0261018304044363).

CASEY, D.L. (2016) 'The Casey Review: A Review into Opportunity and Integration' retrieved 10 April 2018 from https://assets.publishing.service.gov.uk/government/uploads/system/ uploads/attachment_data/file/575973/The_Casey_Review_Report.pdf.

Chew-Graham, C., C. BAshir, K. Chantler, E. Burman \& J. Batsleer (2002). 'South Asian Women, Psychological Distress and Self-Harm: Lessons for Primary Care Trusts', Health and Social Care in the Community 10, 339-47 (https://doi.org/10.1046/j.1365-2524.2002. 00382.x).

Devries, K.M., J.Y. MaK, L.J. Bacchus, J.C. Child, G. Falder, M. Petzold, J. Astbury \& C.H. WATTS (2013) 'Intimate Partner Violence and Incident Depressive Symptoms and Suicide Attempts: A Systematic Review of Longitudinal Studies', PLoS Med 10(5) (https://doi.org/ 10.1371/journal.pmed.1001439).

Dillon, G., R. Hussain, D. Loxton \& S. Rahman (2013). 'Mental and Physical Health and Intimate Partner Violence Against Women: A Review of the Literature', International Journal of Family Medicine, Article ID 313909, 15 pages (https://doi.org/10.1155/2013/313909).

Ferrari, G., R. Agnew-Davies, J. Bailey, L. Howard, E. Howarth, T.J. Peters, L. Sardinha \& G. FEDER (2014) 'Domestic Violence and Mental Health: A Cross-Sectional Survey of Women Seeking Help from Domestic Violence Support Services', Global Health Action 9:29890, n.p. (https://doi.org/10.3402/gha.v9.29890).

Gilbert, P., J. GILBERT \& J. SANGHERA (2004) 'A Focus Group Exploration of the impact of izzat, shame, subordination and entrapment on mental health and service use in South Asian women living in Derby', Mental Health, Religion \& Culture 7, 109-30 (https://doi.org/ 10.1080/13674670310001602418).

Gilchrist, E., R. Johnson, R. Takriti, S. Weston, A. Beech \& M. Kebbel (2003) Domestic Violence Offenders: Characteristics and Offending Related Needs (London: Home Office) retrieved 13 April 2019 from https://webarchive.nationalarchives.gov.uk/20110218141158/ http://rds.homeoffice.gov.uk/rds/pdfs2/r217.pdf.

GILL, A. (2004) 'Voicing the Silent Fear: South Asian Women's Experiences of Domestic Violence', The Howard Journal of Crime and Justice 43, 465-83 (https://doi.org/10.1111/ j.1468-2311.2004.00343.x).

Goodman, L., L. BennetT \& M.A. Dutton (1999) 'Obstacles to Victims' Cooperation with the Criminal Prosecution of their Abusers: The Role of Social Support', Violence and Victims 14, 427-44 (https://doi.org/10.1891/0886-6708.14.4.427).

'Guru Gobind Singh Ji' (2015) in Encyclopaedia Britannica 'Adi Granth: Sikh Sacred Scripture', retrieved 10 April 2018 from http://www.britannica.com/EBchecked/topic/5865/Adi-Granth.

Hegarty, K. (2011) 'Domestic Violence: The Hidden Epidemic Associated with Mental Illness', The British Journal of Psychiatry 198, 169-70 (https://doi.org/10.1192/bjp.bp.110.083758).

Hicks, M.H.-R. \& D. BhugRa (2003). 'Perceived Causes of Suicide Attempts by U.K. South Asian Women', American Journal of Orthopsychiatry 73, 455-62 (https://doi.org/10.1037/00029432.73.4.455). 
Humphreys, C. \& R. Thiara (2003) 'Mental Health and Domestic Violence: "I Call it Symptoms of Abuse" ', The British Journal of Social Work 33, 209-26 (https://doi.org/10.1093/ bjsw/33.2.209).

Hussain, F.A. \& R. Cochrane (2002) 'Depression in South Asian Women: Asian Women's Beliefs on Causes and Cures', Mental Health, Religion \& Culture 5, 285-311 (https:// doi.org/10.1080/13674670210130036).

Husain, M. I., W. WAHEed \& N. Husain (2006) 'Self-Harm in British South Asian Women: Psychosocial Correlates and Strategies for Prevention', Annals of General Psychiatry 5:7 (https://doi.org/10.1186/1744-859X-5-7).

Information for Local Areas on the Change to the Definition of Domestic Violence and Abuse (2013) (C) Crown Copyright 2013 (London: Home Office) retrieved 11 April 2019 from https://assets.publishing.service.gov.uk/government/uploads/system/uploads/attachment_dat a/file/142701/guide-on-definition-of-dv.pdf

Izzidien, S. (2008) 'I Can't Tell People what is Happening at Home': Domestic Abuse within South Asian Communities: The Specific Needs of Women, Children and Young People (London: NSPCC) retrieved 14 April 2019 from https://www.nspcc.org.uk/globalassets/documents/ research-reports/i-cant-tell-people-what-happening-home-report.pdf.

KalRa, G.S., K. BhUi \& D.K. Bhugra (2012) 'Sikhism, Spirituality and Psychiatry', Asian Journal of Psychiatry 5, 339-43 (https://doi.org/10.1016/j.ajp.2012.08.011).

Mckenzie, K., M. Serfaty \& M. Crawford (2003) 'Suicide in Ethnic Minority Groups', The British Journal of Psychiatry 183, 100-1 (https://doi.org/10.1192/bjp.183.2.100).

Mirza, N. (2016) South Asian Women's Experience of Family Abuse: The Role of the Husband's Mother (Centre for Research on Families and Relationships: Briefing 80) retrieved 14 April 2019 from https://www.era.lib.ed.ac.uk/bitstream/handle/1842/14199/CRFR\%20briefing $\% 2080$.pdf? sequence $=1 \&$ is Allowed $=\mathrm{y}$.

Merrill, J. \& J. Owens (1986) 'Ethnic Differences in Self-Poisoning', British Journal of Psychiatry 148, 708-12 (http://dx.doi.org/10.1192/bjp.148.6.708).

PANDE, A. (2017) 'Women in Indian Diaspora: Redefining Self Between Dislocation and Relocation' in: A. PANDE, ed., Women in the Indian Diaspora: Historical Narratives and Contemporary Challenges (Singapore: Springer) 1-12 (http://dx.doi.org/10.1007/978-981-10-59513 1).

RupraI, S. (2016) 'A Sinking Heart': Beliefs of Distress in the Punjabi Community (PhD diss., University of East London) retrieved 14 April 2019 from http://roar.uel.ac.uk/5412/.

Rawal Priyanka \& Singh Jyoti (2014) 'Practice of Dowry and Domestic Violence', Research Journal of Recent Sciences 3. 95-98, retrieved 17 April 2019 from http://www.isca.in/rjrs/ archive/v3/iIVC-2014/17.ISCA-IVC-2014-09FMS-05.php.

Thiara, R.K. \& A. GiLl (2012) Domestic Violence, Child Contact, Post-Separation Violence: Issues for South Asian and African-Caribbean Women and Children: A Report of Findings (London: NSPCC).

Trevillion, K., S. Oram, G. Feder, L.M. Howard (2012) 'Experiences of Domestic Violence and Mental Disorders: A Systematic Review and Meta-Analysis', PLoS ONE 7(12): e51740 (http://dx.doi.org/10.1371/journal.pone.0051740).

World Health Organisation (2016) Global Plan of Action: Health Systems Address Violence Against Women and Girls, retrieved 26 April 2018 from http://www.who.int/iris/handle/ $10665 / 251664$. 